(2) Open Access Full Text Article

\title{
In-hospital resuscitation: opioids and other factors influencing survival
}

\author{
This article was published in the following Dove Press journal: \\ Therapeutics and Clinical Risk Management \\ 10 December 2009 \\ Number of times this article has been viewed
}

\section{Karamarie Fecho' \\ Freeman Jackson' \\ Frances Smith' \\ Frank J Overdyk ${ }^{2}$}

'Department of Anesthesiology, University of North Carolina, Chapel Hill, North Carolina, USA; ${ }^{2}$ Department of Anesthesia and Perioperative Medicine, Medical University of South Carolina, Charleston, South Carolina, USA

Correspondence: Karamarie Fecho Department of Anesthesiology, University of North Carolina, Chapel Hill,

North Carolina 27599-7010, USA

$\mathrm{Tel}+\mathrm{I}(919)-966-1470$

$\mathrm{Fax}+\mathrm{I}(919)-966-4873$

Email kfecho@aims.unc.edu
Purpose: "Code Blue" is a standard term used to alertt hospital staff that a patient requires resuscitation. This study determined rates of survival from Code Blue events and the role of opioids and other factors on survival.

Methods: Data derived from medical records and the Code Blue and Pharmacy databases were analyzed for factors affecting survival.

Results: During 2006, rates of survival from the code only and to discharge were $25.9 \%$ and $26.4 \%$, respectively, for Code Blue events involving cardiopulmonary resuscitation (CPR; $\mathrm{N}=216)$. Survival rates for events not ultimately requiring CPR $(\mathrm{N}=77)$ were higher, with $32.5 \%$ surviving the code only and $62.3 \%$ surviving to discharge. For CPR events, rates of survival to discharge correlated inversely with time to chest compressions and defibrillation, precipitating event, need for airway management, location and age. Time of week, witnessing, postoperative status, gender and opioid use did not influence survival rates. For non-CPR events, opioid use was associated with decreased survival. Survival rates were lowest for patients receiving continuous infusions $(P<0.01)$ or iv boluses of opioids $(P<0.05)$.

Conclusions: One-quarter of patients survive to discharge after a CPR Code Blue event and two-thirds survive to discharge after a non-CPR event. Opioids may influence survival from non-CPR events.

Keywords: code blue, survival, opioids, cardiopulmonary resuscitation, cardiac arrest, patient safety

\section{Introduction}

"Code Blue" is one of numerous standardized terminologies in the uniform hospital code system developed by the Hospital Association of Southern California, United States, in 2000 and used to indicate that a patient requires immediate resuscitation. ${ }^{1}$ Cardiac arrest is the most common trigger for a Code Blue emergency, but respiratory depression and/or hypotension can also serve as precipitating or contributing factors. Cardiopulmonary resuscitation (CPR) has been in widespread use as a resuscitation technique since scientific evidence of its success was introduced in $1960 .^{2}$ Research on factors that contribute to the effectiveness of CPR is sparse, although several factors have been identified, including the time to chest compressions and defibrillation, ${ }^{3-6}$ the time of day/week, ${ }^{7}$ and characteristics such as patient age and gender. ${ }^{8-9}$

Opioids are commonly used for the treatment of acute pain, particularly in the hospital setting. Yet concerns continue to mount related to the safety of opioids, outside or within a hospital setting. ${ }^{10-12}$ Indeed, opioid-induced respiratory depression and hypotension are life-threatening complications that can arise quickly and are 
not always recognized, even when continuous monitoring devices are employed. ${ }^{13-14}$ The relationship between opioids and rates of survival from Code Blue emergencies has not been explored.

The aims of this study are to: (1) determine rates of survival from Code Blue events and survival to hospital discharge; and, (2) explore factors associated with decreased rates of survival from Code Blue events, specifically the use of opioids.

\section{Methods}

All study procedures were approved by the Institutional Review Board at the University of North Carolina (UNC) at Chapel Hill (\#07-1034).

\section{Primary data sources}

The primary data sources were the Department of Patient Safety and Performance Improvement's Code Blue database, the Pharmacy Department's database, and patient medical records at UNC Hospitals, a large, university-based, tertiary care hospital.

\section{Data extraction and dataset generation}

UNC hospitals incorporated many of the "Utstein Style" code blue reporting guidelines ${ }^{15}$ into a standardized Code Blue reporting form. The form was completed by the charge nurse and verified by the attending physician at the time of the Code Blue emergency. The form contained checkboxes for the precipitating cause of the event, the hospital location, whether the event was witnessed, and whether airway management (intubation, positive pressure ventilation, mask ventilation) was required. Data on hospital discharge data (dead or alive; date) were entered into this database manually, after patient follow-up by the database administrator. Included in the Code Blue database were events requiring CPR (CPR events) and events not requiring CPR but triggered by respiratory depression or hypotension and suspected initially to require CPR (non-CPR events). The Code Blue database did not contain data on terminal patients receiving palliative care. The Code Blue database was queried for all fields of data from the year 2006, including patient medical record numbers. The Pharmacy Database was queried for all narcotics (drug, route of administration, time of administration) administered in the 24 hours before each event, using patient medical record numbers and the date and time of the event to identify patients. Actual narcotic dosages administered to each patient were not available in the database. Results from both queries were transferred to two separate MS Excel (Microsoft, Inc., Seattle, WA) datasets. Data related to patient demographics, diagnoses, comorbidities and operative history were extracted from paper medical records and manually entered into a third MS Excel dataset. SPSS (v. 16.0; SPSS, Inc., Chicago, IL) was used to merge the MS Excel datasets and create a new dataset, using patient medical record numbers and the dates and times of each event as index variables. The resulting dataset was then stripped of all identifiers and SPSS was used for data clean-up, variable building and variable transformations. A new variable was created to distinguish codes occurring on weekdays (Monday 07:00 to Friday 22:59) from those occurring on weekends (Friday 23:00 to Monday 06:59), using the same definitions as Peberdy et al. ${ }^{7}$

\section{Primary outcome variables}

The primary endpoint variables were patient survival from the event (Survived Code Only) and patient survival to hospital discharge (Survived to Discharge).

\section{Statistical analysis}

SPSS (v. 16) was used for statistical analysis. CPR events and non-CPR events were analyzed separately. A retrospective power analysis indicated that the sample size was sufficient to report survival rates for both $\mathrm{CPR}$ and non-CPR events with a 95\% confidence level and 10\% confidence interval. Descriptive statistics were generated and the two survival groups (Survived Code Only and Survived to Discharge) were individually compared to those who did not survive the code across select variables using Chi Square or Fisher's Exact test for categorical variables or Analysis of Variance for continuous variables. Missing data points were excluded from the statistical analysis. Data on the relationship between opioids and survival were analyzed overall and stratified by route of opioid administration. For all analyses, $\alpha=0.05$.

\section{Results}

Over the one year study period, 222 Code Blue emergency calls involved CPR and 83 Code Blue emergency calls were non-CPR events precipitated by respiratory depression and/or hypotension and suspected initially to require CPR. Six of the CPR events and 6 of the non-CPR events took place in the Emergency Department and outcomes were unknown. These were excluded from further analysis, thereby reducing the number of CPR events to 216 and non-CPR events to 77.

For CPR events, 56 (25.9\%) subjects survived the code only and $57(26.4 \%)$ subjects survived to hospital discharge (Table 1). The time to chest compressions $(P<0.05)$ and defibrillation $(P<0.01)$ was significantly shorter for 
Table I Survival from cardiopulmonary resuscitation events, overall and by event and demographic characteristics ${ }^{\mathrm{a}}$

\begin{tabular}{|c|c|c|c|c|}
\hline $\begin{array}{l}\text { Total } \\
\mathbf{N}=216\end{array}$ & $\begin{array}{l}\text { Did not survive } \\
\text { code } \\
N=103(47.7 \%)\end{array}$ & $\begin{array}{l}\text { Survived code } \\
\text { only } \\
\mathbf{N}=\mathbf{5 6}(\mathbf{2 5 . 9 \% )}\end{array}$ & $P^{b}$ & $\begin{array}{l}\text { Survived to } \\
\text { discharge } \\
\mathbf{N}=57(26.4 \%)\end{array}$ \\
\hline
\end{tabular}

\begin{tabular}{|c|c|c|c|c|c|c|}
\hline \multicolumn{7}{|l|}{ Mean \pm SEM } \\
\hline $\begin{array}{l}\text { Time to chest } \\
\text { compressions }\end{array}$ & $3.13 \pm 0.62$ & $4.64 \pm 1.32$ & $1.91 \pm 1.32$ & NS & $1.92 \pm 0.46$ & $<0.05$ \\
\hline Time to defibrillation & $10.76 \pm 1.45$ & $14.75 \pm 1.95$ & $7.10 \pm 1.83$ & NS & $4.14 \pm 1.32$ & $<0.01$ \\
\hline \multicolumn{7}{|l|}{$\mathbf{N}(\%)$} \\
\hline \multicolumn{7}{|l|}{ Precipitating cause } \\
\hline Respiratory depression & 34 (I5.7\%) & $10(9.7 \%)$ & $10(17.9 \%)$ & NS & 14 (24.6\%) & $<0.01$ \\
\hline Hypotension & $18(8.3 \%)$ & $8(7.8 \%)$ & $3(5.4 \%)$ & & 7 (I2.3\%) & \\
\hline Lethal arrhythmia/MI & $39(18.1 \%)$ & $20(19.4 \%)$ & $13(23.2 \%)$ & & $6(10.5 \%)$ & \\
\hline Multiple causes & $36(16.7 \%)$ & $20(19.4 \%)$ & $13(23.2 \%)$ & & $3(5.3 \%)$ & \\
\hline Other/unknownc & 89 (4I.2\%) & 45 (43.7\%) & 17 (30.4\%) & & 27 (47.4\%) & \\
\hline \multicolumn{7}{|l|}{ Location } \\
\hline NICU/PICU & $35(16.2 \%)$ & 10 (9.7\%) & 7 (I2.5\%) & $<0.05$ & 18 (31.6\%) & $<0.0005$ \\
\hline Women's and children's & $10(4.6 \%)$ & $4(3.9 \%)$ & $\mathrm{I}(\mathrm{I} .8 \%)$ & & $5(8.8 \%)$ & \\
\hline Cardiac care unit & $22(10.2 \%)$ & $13(12.6 \%)$ & $3(5.4 \%)$ & & $6(10.5 \%)$ & \\
\hline ICU & 70 (32.4\%) & $33(32.0 \%)$ & 24 (42.9\%) & & $13(22.8 \%)$ & \\
\hline ED & $29(13.4 \%)$ & $24(23.3 \%)$ & $3(5.4 \%)$ & & $2(3.5 \%)$ & \\
\hline Other ${ }^{d}$ & $50(23.1 \%)$ & $19(18.4 \%)$ & 18 (32.1\%) & & $13(22.8 \%)$ & \\
\hline \multicolumn{7}{|l|}{ Witnessed event } \\
\hline Yes & $176(81.5 \%)$ & $82(79.6 \%)$ & 45 (80.4\%) & NS & 49 (86.0\%) & NS \\
\hline No & $30(13.9 \%)$ & $17(16.5 \%)$ & 7 (I2.5\%) & & $6(10.5 \%)$ & \\
\hline Not recorded & $10(4.6 \%)$ & $4(3.9 \%)$ & $4(7.1 \%)$ & & $2(3.5 \%)$ & \\
\hline \multicolumn{7}{|l|}{ Weekend event } \\
\hline Yes & 47 (21.8\%) & $20(19.4 \%)$ & II (19.6\%) & NS & $16(28.1 \%)$ & NS \\
\hline No & $128(59.3 \%)$ & $58(56.3 \%)$ & 37 (66.1\%) & & $33(57.9 \%)$ & \\
\hline Not recorded & $4 \mathrm{l}(19.0 \%)$ & $25(24.3 \%)$ & $8(14.3 \%)$ & & $8(14.0 \%)$ & \\
\hline \multicolumn{7}{|l|}{ Airway management } \\
\hline Yes & $106(49.1 \%)$ & $60(58.3 \%)$ & $25(44.6 \%)$ & NS & $21(36.8 \%)$ & $<0.05$ \\
\hline No & $104(48.1 \%)$ & $40(38.8 \%)$ & $30(53.6 \%)$ & & 34 (59.6\%) & \\
\hline Not recorded & $6(2.8 \%)$ & $3(2.9 \%)$ & $\mathrm{I}(\mathrm{I} .8 \%)$ & & $2(3.5 \%)$ & \\
\hline \multicolumn{7}{|l|}{$\begin{array}{l}\text { Opioid administration } \\
\text { within } 24 \mathrm{~h} \text { of event }\end{array}$} \\
\hline Yes & $92(42.6 \%)$ & 39 (37.9\%) & $30(53.6 \%)$ & NS & $23(40.4 \%)$ & NS \\
\hline \multirow[t]{2}{*}{ No } & $124(57.4 \%)$ & $64(62.1 \%)$ & $26(46.4 \%)$ & & $34(59.6 \%)$ & \\
\hline & $\mathbf{N}=196$ & $\mathbf{N}=92$ & $\mathbf{N}=\mathbf{5 4}$ & & $\mathbf{N}=\mathbf{5 0}$ & \\
\hline \multicolumn{7}{|l|}{ Event $72 \mathrm{~h}$ postoperative } \\
\hline Yes & $5(2.6 \%)$ & $3(3.3 \%)$ & $2(3.7 \%)$ & NS & $0(0.0 \%)$ & NS \\
\hline No & I9I (97.4\%) & 89 (96.7\%) & 52 (96.3\%) & & $50(100.0 \%)$ & \\
\hline \multicolumn{7}{|l|}{ Age (years) } \\
\hline$\leq 2$ & 35 (17.9\%) & $8(8.7 \%)$ & $8(14.8 \%)$ & NS & 19 (38.0\%) & $<0.0005$ \\
\hline $3-64$ & $100(51.0 \%)$ & $53(57.6 \%)$ & 25 (46.3\%) & & 22 (44.0\%) & \\
\hline$\geq 65$ & 61 (31.I\%) & 31 (33.7\%) & $2 \mathrm{I}(38.9 \%)$ & & $9(18.0 \%)$ & \\
\hline \multicolumn{7}{|l|}{ Gender } \\
\hline Male & $124(63.3 \%)$ & 60 (65.2\%) & 36 (66.7\%) & NS & 28 (56.0\%) & NS \\
\hline Female & 72 (36.7\%) & 32 (34.8\%) & 18 (33.3\%) & & 22 (44.0\%) & \\
\hline
\end{tabular}

aThe table shows the characteristics of patients who survived or did not survive CPR Code Blue Events. Demographic data and data on operative history were missing for a subset of patients $(n=26)$. ${ }^{\text {TT }}$ The two survival groups were independently compared to the group who did not survive the event, using Chi square or Fisher's Exact Test for categorical values and analysis of variance (Student's $t$ test) for continuous variables.

'The precipitating cause was listed as Other for $28.1 \%$ of events and Unknown for $71.9 \%$ of events.

'Other represents hospital floor locations or procedural suites.

Abbreviations: MI, myocardial infarction; NICU/PICU, neonatal or pediatric intensive care unit; ICU, intensive care unit; ED, emergency department; NS, not significant. 
those who survived to discharge compared to those who did not survive the code. The precipitating cause of the event differed for subjects who survived to discharge compared to those who did not survive the code $(P<0.01)$. Respiratory depression was more common, and lethal rrhythmia/myocardial infarction or multiple causes were less common, among those who survived to discharge compared to those who did not survive the code. The location of the code also differed for those who survived to discharge $(P<0.0005)$. Compared to subjects who did not survive the code, subjects who survived to discharge were more frequently in the Neonatal Intensive Care Unit/Pediatric Intensive Care Unit (NICU/PICU) and less frequently in the emergency department. The proportion of CPR events that were witnessed or that occurred on weekends were similar among subjects who survived to discharge compared to subjects who did not. However, the need for airway management was less common among subjects who survived to discharge compared to those who did not $(P<0.05)$. The use of opioids, postoperative status and gender composition was similar among subjects who survived to discharge and those who did not survive the code, but subjects who survived to discharge had a greater proportion of subjects $\leq 2$ years and a smaller proportion of subjects $\geq 65$ years $(P<0.0005)$. Subjects who survived the code only were similar to those who did not survive the code in every examined factor except for location. Subjects who survived the code only were more likely to be in the NICU/PICU, and less likely to be in the emergency department, than those who did not survive the code $(P<0.05)$.

Survival rates were higher for non-CPR events $(\mathrm{N}=77)$, with $25(35.2 \%)$ subjects surviving the code only and $48(62.3 \%)$ subjects surviving to discharge (Table 2). Opioid use was the only factor that differed among subjects who survived compared to subjects who did not survive the code. Opioid use was less common among subjects who survived to discharge compared to those who did not survive the code $(P<0.05)$ and a similar trend was apparent for those who survived the code only $(P<0.10)$.

Thirty-three (42.9\%) subjects received at least one opioid within 24 hours of the non-CPR event (Table 3). Morphine and fentanyl were the primary opioids administered and these were administered to 4 (5.2\%) subjects as continuous infusions, $4(5.2 \%)$ subjects as patient-controlled analgesia (PCA) and $8(10.4 \%)$ subjects as iv boluses. Hydromorphone was administered as an iv bolus to $1(1.3 \%)$ subject. Oxycodone was administered orally to 3 (3.9\%) subjects and $13(16.9 \%)$ subjects received IV boluses of morphine or fentanyl in combination with oral oxycodone. When subjects receiving opioids through each route of administration were compared to those who did not receive opioids, rates of survival were found to be significantly lower among those who received continuous infusions or iv boluses of morphine or fentanyl (Table 3). None of the subjects who received a continuous infusion of morphine or fentanyl survived to hospital discharge compared to $30(68.2 \%)$ subjects who did not receive opioids $(P<0.001)$. Rates of survival to hospital discharge also were lower for subjects who received iv boluses of morphine or fentanyl $(P<0.05 \%)$. Of note, all patients who did not receive opioids survived the code, whereas $50.0 \%$ of subjects who received continuous infusions, $22.9 \%$ of subjects who received iv boluses and $15.4 \%$ of subjects who received iv boluses in combination with oral oxycodone did not survive the code. Four subjects $(5.2 \%)$ received at least one injection of naloxone before the non-CPR event and only 2 of those $(50.0 \%)$ survived to discharge.

\section{Discussion}

While CPR has been formally studied only in the last several decades, it has been described in texts that date back to Biblical times. Elisha is said to have laid his lips on a child's lifeless body and, with two stretches of his body upon the child, brought the child back to life. Modern CPR dates back to 1960 , when closed chest cardiac massage was proven to be beneficial in animal studies, ${ }^{2}$ and CPR remains in widespread use, both in-hospital and out-of-hospital. CPR is the first treatment approach taken during an in-hospital Code Blue emergency involving cardiac arrest. Systematic research on the effectiveness and long-term outcomes of different modes of resuscitation began only recently, driven in large part by the "Utstein Style" reporting recommendations of a task force drawn from members of the American Heart Association, the European Resuscitation Council, the Heart and Stroke Foundation of Canada, the Australian Resuscitation Council, and the Resuscitation Council of Southern Africa. ${ }^{15}$ Despite the long history of resuscitation, only recently have researchers investigated the effectiveness of CPR, in terms of both short- and long-term outcomes, and factors contributing to survival.

The primary aim of the present study was to determine rates of survival from the Code Blue event only and to hospital discharge. A secondary aim was to explore factors influencing survival, specifically the use of opioids, as recent concerns have been raised regarding the safety of opioids, even in a hospital setting with standard continuous monitoring. ${ }^{10-14} \mathrm{We}$ emphasize that our Code Blue database does not contain data from calls to our Rapid Response Team (RRT, otherwise 
Table 2 Survival from non-cardiopulmonary resuscitation events, overall and by event and demographic characteristics ${ }^{\mathrm{a}}$

$\begin{array}{lllll}\text { Total } & \text { Did not survive } & \text { Survived code } & P^{\mathrm{b}} & \begin{array}{l}\text { Survived to } \\ \text { discharge }\end{array} \\ \mathrm{N}=\mathbf{7 7} & \text { code } & \text { only } & \mathrm{N}=\mathbf{4 8}(62.3 \%) \\ & \mathrm{N}=\mathbf{4 ( 5 . 2 \% )} & \mathrm{N}=\mathbf{2 5}(32.5 \%) & & \mathbf{N}\end{array}$

\section{$\mathbf{N}(\%)$}

Precipitating cause

\begin{tabular}{|c|c|c|c|c|c|c|}
\hline Respiratory depression & $47(61.0 \%)$ & I (25.0\%) & $13(52.0 \%)$ & NS & $33(68.8 \%)$ & NS \\
\hline Hypotension & $15(19.5 \%)$ & I (25.0\%) & $4(16.0 \%)$ & & $10(20.8 \%)$ & \\
\hline Both & $15(19.5 \%)$ & $2(50.0 \%)$ & $8(32.0 \%)$ & & $5(10.4 \%)$ & \\
\hline \multicolumn{7}{|l|}{ Location } \\
\hline $\mathrm{NICU} / \mathrm{PICU}$ & $0(0.0 \%)$ & $0(0.0 \%)$ & $0(0.0 \%)$ & \multirow[t]{6}{*}{ NS } & $0(0.0 \%)$ & \multirow[t]{6}{*}{ NS } \\
\hline Women's and children's & $6(7.8 \%)$ & $0(0.0 \%)$ & $2(8.0 \%)$ & & $4(8.3 \%)$ & \\
\hline Cardiac Care Unit & 7 (9.1\%) & I (25.0\%) & $2(8.0 \%)$ & & $4(8.3 \%)$ & \\
\hline ICU & $29(37.7 \%)$ & $3(75.0 \%)$ & II (44.0\%) & & 15 (3I.3\%) & \\
\hline ED & $0(0.0 \%)$ & $0(0.0 \%)$ & $0(0.0 \%)$ & & $0(0.0 \%)$ & \\
\hline Other ${ }^{c}$ & $35(45.5 \%)$ & $0(0.0 \%)$ & $10(40.0 \%)$ & & $25(52.1 \%)$ & \\
\hline \multicolumn{7}{|l|}{ Witnessed event } \\
\hline Yes & $66(85.7 \%)$ & $4(100.0 \%)$ & $23(92.0 \%)$ & \multirow[t]{3}{*}{ NS } & 39 (8I.3\%) & \multirow[t]{3}{*}{ NS } \\
\hline No & $3(3.9 \%)$ & $0(0.0 \%)$ & $0(0.0 \%)$ & & $3(6.3 \%)$ & \\
\hline Not recorded & $8(10.4 \%)$ & $0(0.0 \%)$ & $2(8.0 \%)$ & & $6(12.5 \%)$ & \\
\hline \multicolumn{7}{|l|}{ Weekend event } \\
\hline Yes & $22(28.6 \%)$ & $2(50.0 \%)$ & $9(36.0 \%)$ & \multirow[t]{3}{*}{ NS } & II (22.9\%) & \multirow[t]{3}{*}{ NS } \\
\hline No & $46(59.7 \%)$ & $2(50.0 \%)$ & 14 (56.0\%) & & 30 (62.5\%) & \\
\hline Not recorded & $9(11.7 \%)$ & $0(0.0 \%)$ & $2(8.0 \%)$ & & 7 (I4.6\%) & \\
\hline \multicolumn{7}{|l|}{ Airway management } \\
\hline Yes & $14(18.2 \%)$ & $2(50.0 \%)$ & 7 (28.0\%) & \multirow[t]{3}{*}{ NS } & $5(10.4 \%)$ & \multirow[t]{3}{*}{ NS } \\
\hline No & $62(80.5 \%)$ & $2(50.0 \%)$ & 18 (72.0\%) & & 42 (87.5\%) & \\
\hline Not recorded & I (I.3\%) & $0(0.0 \%)$ & $0(0.0 \%)$ & & I (2.I\%) & \\
\hline \multicolumn{7}{|l|}{ Opioid administration } \\
\hline \multicolumn{7}{|l|}{ within $24 \mathrm{~h}$ of event } \\
\hline Yes & $33(42.9 \%)$ & $4(100.0 \%)$ & II (44.0\%) & \multirow[t]{3}{*}{ NS } & 18 (37.5\%) & \multirow[t]{3}{*}{$<0.05$} \\
\hline \multirow[t]{2}{*}{ No } & $44(57.1 \%)$ & $0(0.0 \%)$ & 14 (56.0\%) & & $30(62.5 \%)$ & \\
\hline & $\mathbf{N}=\mathbf{7 5}$ & $\mathbf{N}=\mathbf{4}$ & $\mathbf{N}=\mathbf{2 5}$ & & $\mathbf{N}=46$ & \\
\hline \multicolumn{7}{|l|}{ Event $72 \mathrm{~h}$ postoperative } \\
\hline Yes & $3(4.0 \%)$ & $0(0.0 \%)$ & I ( $(4.0 \%)$ & \multirow[t]{2}{*}{ NS } & $2(4.3 \%)$ & \multirow[t]{2}{*}{ NS } \\
\hline No & $72(96.0 \%)$ & $4(100.0 \%)$ & $24(96.0 \%)$ & & $44(95.7 \%)$ & \\
\hline \multicolumn{7}{|l|}{ Age (years) } \\
\hline$\leq 2$ & I (I.3\%) & $0(0.0 \%)$ & $0(0.0 \%)$ & \multirow[t]{3}{*}{ NS } & I (2.2\%) & \multirow[t]{3}{*}{ NS } \\
\hline $3-64$ & $56(74.7 \%)$ & $4(100.0 \%)$ & $20(80.0 \%)$ & & $32(69.6 \%)$ & \\
\hline$\geq 65$ & $18(24.0 \%)$ & $0(0.0 \%)$ & $5(20.0 \%)$ & & $13(28.3 \%)$ & \\
\hline \multicolumn{7}{|l|}{ Gender } \\
\hline Male & $39(52.0 \%)$ & $3(75.0 \%)$ & II (44.0\%) & \multirow[t]{2}{*}{ NS } & 25 (54.3\%) & \multirow[t]{2}{*}{ NS } \\
\hline Female & $36(48.0 \%)$ & I (25.0\%) & 14 (56.0\%) & & 21 (45.7\%) & \\
\hline
\end{tabular}

aThe table shows the characteristics of patients who survived or did not survive respiratory depression- and/or hypotension-precipitated non-CPR Code Blue Events. Demographic data and data on operative history were missing for a subset of patients $(n=2)$.

'The two survival groups were independently compared to the group who did not survive the event, using Chi square or Fisher's Exact Test for categorical values and analysis of variance (Student's $t$ test) for continuous variables.

'Other represents hospital floor locations or procedural suites.

Abbreviations: MI, myocardial infarction; NICU/PICU, neonatal or pediatric intensive care unit; ICU, intensive care unit; ED, emergency department; NS, not significant. 
known as medical emergency team), which was operational during the study period, nor does it contain data on terminal patients receiving palliative care. Our results indicate that $26.4 \%$ of patients survive to discharge after a CPR event. Rates of survival are higher for non-CPR events, with $62.3 \%$ of patients surviving to discharge. These survival rates are in the same range as previously published rates. ${ }^{4-6,16,17}$

Patients who survived to discharge after a CPR event are more likely to be located in the NICU/PICU and be $\leq 2$ years of age, compared to patients who did not survive the code. This finding probably relates to the relatively better health status of very young children and the plasticity of their central nervous system. In addition, the etiology of cardiac arrest in children is more frequently respiratory-related, rather than cardiac, as is the case in adults. ${ }^{18}$ Prior studies suggest decreased rates of survival from CPR among the elderly, ${ }^{9,19,20}$ although other studies have not found an effect of age on survival. ${ }^{16}$ The findings reported here indicate a greater proportion of patients $\geq 65$ years of age among those who did not survive the CPR event compared to those who survived to discharge.

Prior studies have shown that females have higher rates of survival from cardiac arrest than males, ${ }^{9}$ although discrepancies exist. ${ }^{21}$ In the current study, rates of survival from CPR events and to hospital discharge were similar among males and females. These findings suggest that an innate difference between genders in the response to CPR does not exist; rather, multiple factors likely contribute to any gender disparity in survival. ${ }^{22}$

The 2005 Advanced Cardiac Life Support guidelines recommend that chest compressions be started immediately upon reaching a Code Blue patient. ${ }^{3}$ This recommendation is based on the results of studies demonstrating that the rapid onset of chest compressions increases the odds of survival after cardiac arrest. Recent findings also demonstrate a relationship between delayed defibrillation and decreased survival after in-hospital cardiac arrest. ${ }^{4,5}$ The present results confirm the importance of a rapid onset of chest compressions and defibrillation by showing that the time to chest compressions and defibrillation is shorter among patients who survive to discharge after a CPR event compared to those who did not survive the code. The time to chest compressions and defibrillation is influenced by numerous factors, including the location of the event, the experience level of the responder and other unknown factors. ${ }^{4,5}$ Nevertheless, the current findings reinforce the importance of rapid action and early resuscitation efforts.

A recent study showed that rates of survival from in hospital cardiac arrest are lower on weekends than on weekdays. ${ }^{7}$ The authors suggest that the difference in survival rates is related to a difference in hospital staffing on weekends compared to weekdays. They also note that the difference is much smaller when controlled for the presence or absence of continuous respiratory monitors, which are routinely deployed in stepdown and intensive care units. In our study, the proportion of patients who survived CPR events occurring on weekends was similar to those occurring during weekdays, which likely reflects the fact that the majority of our patients were in a continuously monitored setting and had a witnessed cardiac arrests. In the Peberdy et $\mathrm{al}^{7}$ study, the only location in which there was no difference in survival between weekends and weekdays was in the emergency department, which is in agreement with the present findings.

One of the aims of the present study was to explore the relationship between opioids and rates of survival from Code Blue emergencies. The appropriateness of monitoring patients receiving opioids has been called into question by

Table 3 Route of opioid administration before non-cardiopulmonary resuscitation events $(N=77)^{\text {a }}$

\begin{tabular}{|c|c|c|c|c|c|c|c|c|c|c|c|}
\hline & $\begin{array}{l}\text { No opioids } \\
\mathbf{N}=44 \\
(57.5 \%)\end{array}$ & $\begin{array}{l}\text { Continuous } \\
\text { infusion } \\
N=4(5.2 \%)\end{array}$ & $P^{b}$ & $\begin{array}{l}P^{P C A} \\
N=4 \\
(5.2 \%)\end{array}$ & $P^{b}$ & $\begin{array}{l}\text { IV bolus } \\
\mathbf{N}=9 \\
\text { ( I I.7\%) }\end{array}$ & $P^{b}$ & $\begin{array}{l}\text { Oral } \\
N=3 \\
(3.9 \%)\end{array}$ & $P^{b}$ & $\begin{array}{l}\text { IV Bolus and } \\
\text { oral } \\
N=13(16.9 \%)\end{array}$ & $P^{b}$ \\
\hline $\begin{array}{l}\text { Did not survive } \\
\text { code }\end{array}$ & $0(0.0 \%)$ & $2(50.0 \%)$ & $<0.001$ & $0(0.0 \%)$ & NS & 2 (22.2\%) & $<0.05$ & $0(0.0 \%)$ & NS & $2(15.4 \%)$ & NS \\
\hline $\begin{array}{l}\text { Survived code } \\
\text { only }\end{array}$ & I4 (3I.8\%) & $2(50.0 \%)$ & & $2(50.0 \%)$ & & $2(22.2 \%)$ & & I (33.3\%) & & $3(23.1 \%)$ & \\
\hline $\begin{array}{l}\text { Survived to } \\
\text { discharge }\end{array}$ & 30 (68.2\%) & $0(0.0 \%)$ & & 2 (50.0\%) & & 5 (55.6\%) & & $2(66.7 \%)$ & & 8 (61.5\%) & \\
\hline
\end{tabular}

${ }^{a}$ The table shows opioid use by route of administration within 24 hours of respiratory depression- and hypotension-precipitated non-CPR events. Patients received morphine or fentanyl by continuous infusion, PCA or iv bolus. One patient received hydromorphone by an iv bolus and oral oxycodone (with or without iv boluses) was administered alone to 3 patients and in combination with iv boluses of morphine or fentanyl to 13 patients.

bSurvival rates among subjects who received opioids by each route of administration were compared to those among subjects who did not receive opioids using Chi square or Fisher's Exact Test.

'Patients receiving opioids by PCA also received iv boluses.

Abbreviations: PCA, patient-controlled analgesia; NS, not significant. 
a number of investigators. ${ }^{10-14,23}$ A relationship between opioids and survival from CPR events was not found. However, for non-CPR events, opioids were the only factor found to influence survival. Patients who survived to discharge were less likely to have received opioids within 24 hours of the non-CPR event compared to those who did not survive the code. Interestingly, $4(5.2 \%)$ patients received naloxone within 24 hours of the non-CPR event, presumably for suspected respiratory depression. Morphine and fentanyl were the most common opioids and administration by continuous infusion or iv bolus was found to influence survival. More patients did not survive the code and fewer subjects survived to discharge among patients receiving continuous infusions or iv boluses, compared to those who did not receive opioids. The reason(s) underlying this association is unclear. All of the patients receiving continuous infusions or iv boluses were in an ICU location equipped with standard continuous monitors. An interesting possibility is that patients who received continuous infusions of opioids were on chronic narcotics prior to admission to the hospital, as this is a common practice in these patients who are difficult pain control cases. Recent data suggests these patients may have more frequent central apneas and ataxic breathing patterns that may predispose them to postoperative respiratory complications. ${ }^{24}$

\section{Limitations}

The present study has several limitations that should be considered when interpreting the results. First, the data are derived from a Code Blue reporting form that is completed by charge nurses at the scene of the event. The form is used primarily for clinical purposes and the nurses completing the form are not trained to collect the data for research purposes; therefore, inaccuracies are possible. Second, the possibility exists that some of the events were misclassified as cardiac arrests. Such cases could not be differentiated in the dataset. Third, the data on opioid use are derived from the Pharmacy database which is used primarily for billing and legal purposes, not research, and so inaccuracies are possible and the data are limited; for example, the exact dosages patients were administered were not available for analysis. Furthermore, the reported rates of opioid use are likely lower than actual rates because data on patients who had PCA or continuous infusions of opioids initiated $>24$ hours before the event were not captured. Finally, our finding related to opioid use and survival from non-CPR events should be considered preliminary until assessed more rigorously in a study specifically designed to evaluate this association.

\section{Conclusions}

At our large, university-based, tertiary care hospital, approximately one-quarter of patients survive to discharge after a CPR Code Blue Event and nearly two-thirds of patients survive to discharge after a non-CPR Code Blue Event. Survival from CPR events is inversely correlated with the time to chest compressions and defibrillation and the need for airway management. CPR events precipitated by respiratory depression and occurring among patients in the NICU/PICU or $\leq 2$ years of age have higher rates of survival. Survival from CPR events is not influenced by time of week, witnessing, postoperative status, gender or the use of opioids. Survival from non-CPR events appears to be influenced by the use of opioids within 24 hours of the event.

\section{Acknowledgments}

The authors wish to acknowledge the contributions of Lisa Joyner, MS, and Dennis Pfeiffer, BS, for conducting queries of the Patient Safety and Performance Improvement Code Blue database and the Pharmacy database, respectively. The authors also gratefully acknowledge the clinical input provided by Dr David Ballard in the Department of Anesthesiology at the University of North Carolina at Chapel Hill.

\section{Disclosures}

The authors declare no conflicts of interest.

\section{References}

1. Truesdell A. Meeting hospital needs for standardized emergency codes - the HASC response. J Healthc Prot Manage. 2005;21:77-89.

2. Kouwenhoven WB, Jude JR, Knickerbocker GG. Closed-chest cardiac massage. JAMA. 1960;174:1064-1067.

3. ECC Committee, Subcommittees and Task Forces of the American Heart Association. 2005 international consensus on cardiopulmonary resuscitation and emergency cardiovascular care with treatment recommendations. Circulation. 2005;112:IV-1-IV-211.

4. Chan PS, Krumholz HM, Nichol G, Nallamothu BK; for the American Heart Association National Registry of Cardiopulmonary Resuscitation Investigators. Delayed time to defibrillation after in-hospital cardiac arrest. New Eng J Med. 2008;358:9-17.

5. Chan PS, Nichol G, Krumholz HM, Spertus JA, Nallamothu BK; for the American Heart Association National Registry of Cardiopulmonary Resuscitation Investigators. Hospital variation in time to defibrillation after in-hospital cardiac arrest. Arch Intern Med. 2009;169: $1265-1273$.

6. Ferguson RP, Phelan T, Haddad T, et al. Survival after in-hospital cardiopulmonary resuscitation. South Med J. 2008;101:1-5.

7. Peberdy MA, Ornato JP, Larkin GL, et al. Survival from in-hospital cardiac arrest during nights and weekends. JAMA. 2008;299:785-792.

8. Dahlberg ST. Gender difference in the risk factors for sudden cardiac death. Cardiology. 1990;77(Suppl 2):31-40.

9. Ehlenbach WJ, Barnato AE, Curtis JR, et al. Epidemiologic study of in-hospital cardiopulmonary resuscitation in the elderly. $N$ Engl $J$ Med. 2009;361:22-31. 
10. Cashman JN, Dolin SJ. Respiratory and haemodynamic effects of acute postoperative pain management: Evidence from published data. $\mathrm{Br} J$ Anaesth. 22004;93:212-223.

11. Vila H Jr, Smith RA, Augustyniak MJ, et al. The efficacy and safety of pain management before and after implementation of hospital-wide pain management standards: Is patient safety compromised by treatment based solely on numerical pain ratings? Anesth Analg. 2004;101:474-480.

12. Overdyk F, Carter R, Maddox R. New JCAHO pain standard bigger threat to patient safety than envisioned. Anesth Analg. 2006;102: $1585-1598$

13. Kopka A, Wallace E, Reilly G, Binning A. Observational study of perioperative $P \mathrm{tc}_{\mathrm{CO} 2}$ and $\mathrm{Sp}_{\mathrm{O} 2}$ in non-ventilated patients receiving epidural infusion or patient-controlled analgesia using a single earlobe monitor (TOSCA). Br J Anaesth. 2007;99:567-571.

14. Overdyk F, Carter R, Maddox R, Callura J, Herrin AE, Henriquez C. Continuous oximetry/capnometry monitoring reveals frequent desaturation and bradypnea during patient-controlled analgesia. Anesth Analg. 2007; 105:412-418.

15. Cummins RO, Cochair DC, Cochair MFH, et al. Recommended guidelines for reviewing, reporting, and conducting research on inhospital resuscitation: The in-hospital 'Utstein Style.' Circulation. 1997;95:2213-2239.

16. Saklayen M, Howard L, Markert R. In-hospital cardiopulmonary resuscitation: Survival in 1 hospital and literature review. Medicine. $1995 ; 74: 163-175$
17. Peberdy MA, Kaye W, Ornato JP, et al. Cardiopulmonary resuscitation of adults in the hospital: A report of 14720 cardiac arrests from the National Registry of Cardiopulmonary Resuscitation. Resuscitation. 2003;58:297-308.

18. American Heart Association. Management of respiratory distress and failure. In: Ralsten M, Hazinski MF, Zaritsky AL, Schexnayder SM, Kleinman ME, editors. Pediatric Advanced Life Support. Texas: AHA; 2006;45-60.

19. Taffet GE, Teasdale TA, Luchi RJ. In-hospital cardiopulmonary resuscitation. JAMA. 1988;260:2069-2072.

20. Tresch DD. CPR in the elderly: When should it be performed? Geriatrics. 1991;46:47-50, 54-56.

21. Dittrich H, Gilpin E, Nicod P, Cali G, Henning H, Ross J Jr. Acute myocardial infarction in women: Influence of gender on mortality and prognostic variables. Am J Cardiol. 1988; 62:1-7.

22. Galea S, Blaney S, Nandi A, et al. Explaining racial disparities in incidence of and survival from out-of-hospital cardiac arrest. Am J Epidemiol. 2007;166:534-543.

23. Weinger MB. Dangers of postoperative opioids. APSF workshop and white paper address prevention of postoperative respiratory complications. APSF Newsletter. 2007;21:61, 63-67.

24. Walker JM, Farney RJ, Rhondeau SM, et al. Chronic opioid use is a risk factor for the development of central sleep apnea and ataxic breathing. J Clin Sleep Med. 2007;3:455-461.
Therapeutics and Clinical Risk Management

\section{Publish your work in this journal}

Therapeutics and Clinical Risk Management is an international, peerreviewed journal of clinical therapeutics and risk management, focusing on concise rapid reporting of clinical studies in all therapeutic areas outcomes, safety, and programs for the effective, safe, and sustained use of medicines. This journal is indexed on PubMed Central, CAS,

\section{Dovepress}

EMBase, Scopus and the Elsevier Bibliographic databases. The manuscript management system is completely online and includes a very quick and fair peer-review system, which is all easy to use. Visit http://www.dovepress.com/testimonials.php to read real quotes from published authors. 